\author{
Military Technical College \\ Kobry El-Kobbah, \\ Cairo, Egypt.
}

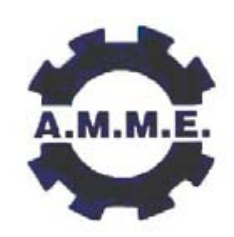

$13^{\text {th }}$ International Conference on Applied Mechanics and Mechanical Engineering.

\title{
THICK AND WELL ADHERENT CARBON LAYERS FOR AUTOMOTIVE INDUSTRY
}

\author{
BATORY D., CLAPA M. and MITURA S.
}

\begin{abstract}
Diamond-like carbon (DLC) layers due to their good mechanical properties are a very interesting material for many industrial applications. But to thick DLC layer results in high internal stress, and is the reason of problems, connected with their poor adhesion and self delamination processes. This problem is widely discussed in world literature. Despite of their very good friction parameters very often the maximum thickness possible to obtain is not sufficient to be applied. Authors of this work propose improvement of adhesion and increase of the thickness of carbon layers by the deposition of $\mathrm{Ti}$ inter and buffer layer between the substrate surface and the carbon layer on the top. Specially to that purpose a new apparatus was designed, which is the connection of impuls magnetron sputtering and plasma assisted chemical vapor deposition in one reaction chamber. Gradient layers were deposited on typical materials which are used in automotive industry and work under friction conditions. Manufactured layers were investigated on SEM and AES, friction coefficient and wear resistance was measured by ball - on - disc method. As the result of investigation it was noticed that carbon layers manufactured in new deposition system are very promising material for automotive applications. It was possible to obtain thick and well adherent DLC layers with keeping of their very good friction parameters.
\end{abstract}

\section{KEY WORDS}

Carbon layers, friction, adhesion, gradient

Institute of Materials Science and Engineering, Technical University of Lodz, ul. Stefanowskiego 1, 90 - 924 Lodz, Poland. E-mail: damian.batory@p.lodz.pl 


\section{INTRODUCTION}

Carbon layers because of their very good tribological, chemical and physical parameters are a very promising material for many industrial applications. Low friction coefficient, high wear resistance and good corrosion parameters found an employment as a protective coatings deposited on machine and engine parts exposed on dry friction existence and on medical tools and implants to improve their corrosion features and protect living tissue against the methalosis [1-6]. There are many methods of carbon films deposition. Their properties strongly depend on the manufacturing technology and process parameters [7]. Despite of their very good physical and chemical parameters the poor adhesion to metal substrates caused by high internal stress limits their application possibilities. Authors of this work propose a new method of adhesion improvement of carbon layers with keeping their very good friction parameters so important in automotive industry. By this method, presented in the previous work [8], a thick and well adherent carbon layers can be deposited.

\section{EXPERIMENTAL}

For the investigation $\mathrm{X} 53 \mathrm{CrMnNi}$ plasma nitrided steel was used. It is typical steel used in automotive industry to produce the engine valves. Microhardness after the nitriding process was about $1300 \mathrm{HV}$, and the roughness was around 0,2. Samples with $\varnothing 25,4$ $\mathrm{mm}$ and $6 \mathrm{~mm}$ high before the deposition process were ultrasonically cleaned in methanol and acetone.

Coating manufacturing process was conducted in a specially designed RF PACVD reactor equipped with magnetron. Wide range of radio frequency power generator with system of the automatic control of reactive atmosphere composition enabled to obtain. Picture of the reactor and structure of Ti:C gradient layers are presented on Figs. 1 and 2.

Samples were placed in specimen holder several millimeters over the water cooled electrode. Deposition conditions was as follows:

1. Before the process pressure in the reaction chamber was $2 * 10^{-3} \mathrm{~Pa}$. Sputtering process was proceeded by 10 min etching in argon atmosphere. Next 0,1 $\mu \mathrm{m} \mathrm{Ti}$ layer was deposited by magnetron sputtering in argon atmosphere.

2. During the sputtering process methane as a source of carbon was introduced into the chamber. Both $\mathrm{Ti}$ and $\mathrm{TiC}$ interlayers attended as the adhesion improvement layer between the DLC coating and the substrate surface.

3. DLC layer was manufactured by RF PACVD method. Pressure during the deposition process was $20 \mathrm{~Pa}$ and the self bias was $-600 \mathrm{~V}$. Thickness of manufactured films was about $2,5 \mu \mathrm{m}$.

Gradient of the chemical composition of Ti:C was studied by AES and SEM. To avoid the spectrum of carbon from the substrate, layers were deposited on silicon wafer for AES and on tungsten surface for SEM.

Roughness parameters were investigated after the nitriding process and after the Ti:C gradient layer deposition process, with use of the profilometer HOMMEL TESTER T1000. Friction coefficient and wear resistance were examined by ball-on-disc method with use of $100 \mathrm{Cr} 6$ and ceramic $\left(\mathrm{ZrO}_{2}\right)$ balls. Sliding speed was 0,1 
$\mathrm{m} / \mathrm{s}$, distance $1000 \mathrm{~m}$ with load of $10 \mathrm{~N}$ for steel ball and $20 \mathrm{~N}$ for ceramic ball under normal humidity conditions. After the investigation wear tracks on the samples and steel balls were studied on the profilometer and the optical microscope.

\section{RESULTS AND DISCUSSION}

According to chemical composition investigation, as it is presented on Fig. 3 increasing concentration of carbon and decreasing concentration of Ti was obtained.

Thin Ti interlayer is visible close to the Si surface. Next with the addition of methane into the chamber concentration of $\mathrm{Ti}$ is decreased probably because of the $\mathrm{TiC}$ carbide formation, which ensure smooth transition into DLC coating, when the sputtering process is finished. Similar situation appears on elements distribution maps on Fig. 4, obtained on tungsten substrate covered with Ti:C gradient layer by SEM EDS method.

Roughness parameters were measured five times on each sample and the results were averaged.

Effects of the investigation presented in Table 1 shows negligible worsening of $\mathrm{Ra}$ and $\mathrm{Rz}$ parameters caused by the deposited layer. But we can see the noticeable improvement of Rku parameter which is a measure of steepness of the amplitude density curve of the roughness profile.

Wear resistance and friction coefficient measurement proves a great friction parameters and high wear resistance of manufactured layers.

As the result of investigation a very low friction coefficient was obtained for steel ball (less then 0,1) as well as for the ceramic $(0,025)$, Fig. 5. Optical microscope studies of the wear track obtained after the examination with the steel ball as the opposite sample, didn't show any diminution of the layer. There was only polished area $240 \mu \mathrm{m}$ wide presented on Fig. 6a. The other situation is presented on Fig. 6b where on the steel ball surface $328 \mu \mathrm{m}$ wide abrasion was observed.

Because of the lack of wear on the sample surface the ceramic ball $\mathrm{ZrO}_{2}$ with doubled load was applied. Finally after the test a wear track with $189 \mathrm{~nm}$ wide and 185 deep abrasion was obtained. But it is worth to notice that the abrasion is rather a result of the layer roughness flattening which is presented on Fig 7.

Figure 7 Profile of the wear track obtained after the ball-on-disc investigation with use of the ceramic ball and $20 \mathrm{~N}$ load.

Table 1. Roughness parameters measured on the profilometer

\begin{tabular}{|lllll|}
\hline & $\mathrm{Ra}$ & $\mathrm{Rt}$ & $\mathrm{Rz}$ & $\mathrm{Rku}$ \\
X53CrMnNi & 0,196 & 1,72 & 1,493 & 4,731 \\
X53CrMnNi with the layer & 0,207 & 1,927 & 1,58 & 3,72 \\
\hline
\end{tabular}




\section{CONCLUSION}

During the investigation following conclusions was reasoned:

1. A new method of deposition presented in this paper let to obtain thick and well adherent Ti:C gradient layers.

2. Ti:C layers don't change for the worse the surface parameters.

3. Low friction coefficients obtained in the examinations make these layers a very promising coating material for many industrial applications where a dry sliding conditions can be observed.

4. Very high wear resistance observed during the investigations makes Ti:C gradient layers a very good protective coatings.

\section{ACKNOWLEDGEMENT}

This work has been financed from the Science Minister's sources, the confines of the Multi-Year Program PW-004 "Development of innovativeness systems of manufacturing and maintenance 2004-2008"; Nr PW-004/ITE/04/2006

This work has been supported by the Ministry of Scientific Research and Information Technology under grant N507 174 32/1697

The author (Damian Batory) is a grant holder of "Mechanizm WIDDOK" project supported by European Social Fund and Polish State (contract number $\mathrm{Z} / 2.10 / \mathrm{II} / 2.6 / 04 / 05 / \mathrm{U} / 2 / 06)$.

\section{REFERENCES}

[1] R. Hauert, An overview on the tribological behavior of diamond - like carbon in technical and medical applications, Tribology International, No. 37, pp. 991 - 1003 (2004).

[2] NANODIAM. New Technologies for medical applications: studying and production of carbon surfaces allowing for controllable bioactivity, Edited by S. Mitura, P. Niedzielski, B. Walkowiak, PWN, Warszawa (2006).

[3] J. Grabarczyk, D. Batory, P Louda, P. Couvrat, I. Kotela, K. Bakowicz - Mitura, Carbon coatings for medical implants, Journal of Achievements in Materials and Manufacturing Engineering, Vol. 20, 1 - 2 , pp. 107-111 (2007).

[4] Constantin R., Miremad B., Performance of hard coatings, made by balanced and unbalanced magnetron sputtering, for decorative applications, Surface \& Coatings Technology, No. 120 - 121, pp. $728-733$ (1999).

[5] Ali Erdemir, Genesis of superlow friction and wear in diamondlike carbon films, Tribology International, No. 37, pp. 1005 - 1012 (2004).

[6] $\mathrm{Li}-\mathrm{Ye}$ - Huang i inni, Nano - scratch and fretting wear study of DLC coatings for biomedical application, Diamond and Related Materials, No 10, pp. 1448 1456 (2001).

[7] J. Robertson, Diamon-like amorphous carbon, Materials Science and Engineering, no. 37, pp. $129-281$ (2002). 
[8] M. Cłapa, D. Batory: Improving adhesion and wear resistance of carbon coatings using Ti:C gradient layers, Journal of Achievements in Materials and Manufacturing Engineering, Vol. 20, 1-2, pp. $415-418$ (2007).

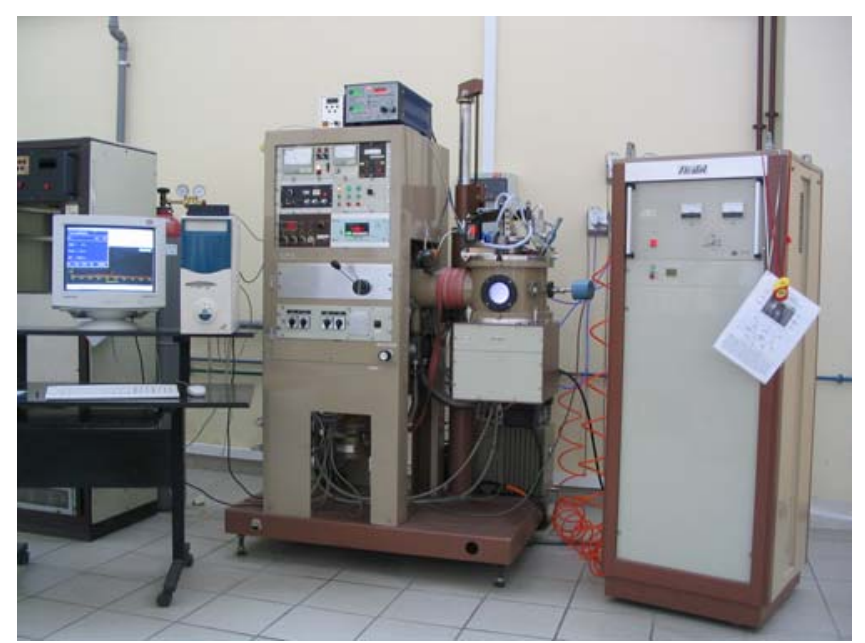

Fig. 1. Picture of the reactor used in presented investigation.

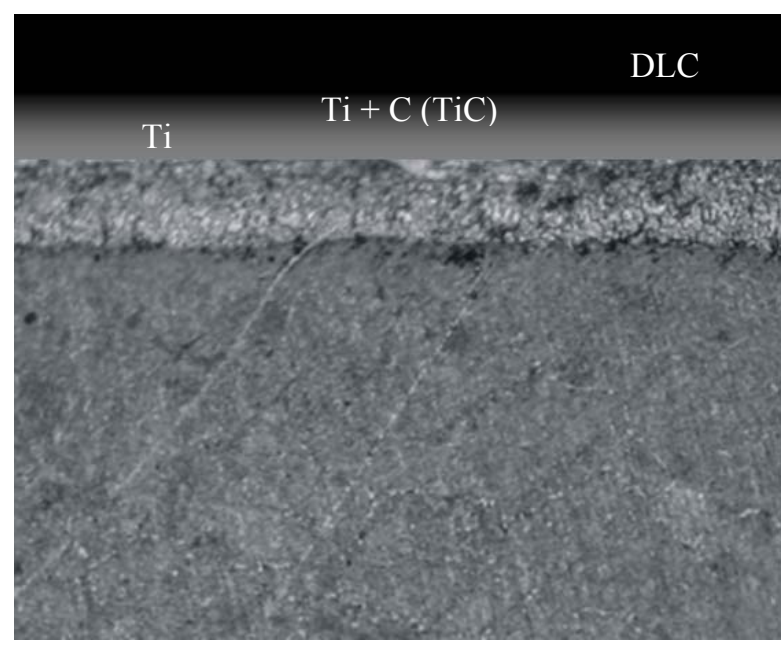

Fig. 2. Schematic composition of Ti:C gradient layer deposited on nitride surface.

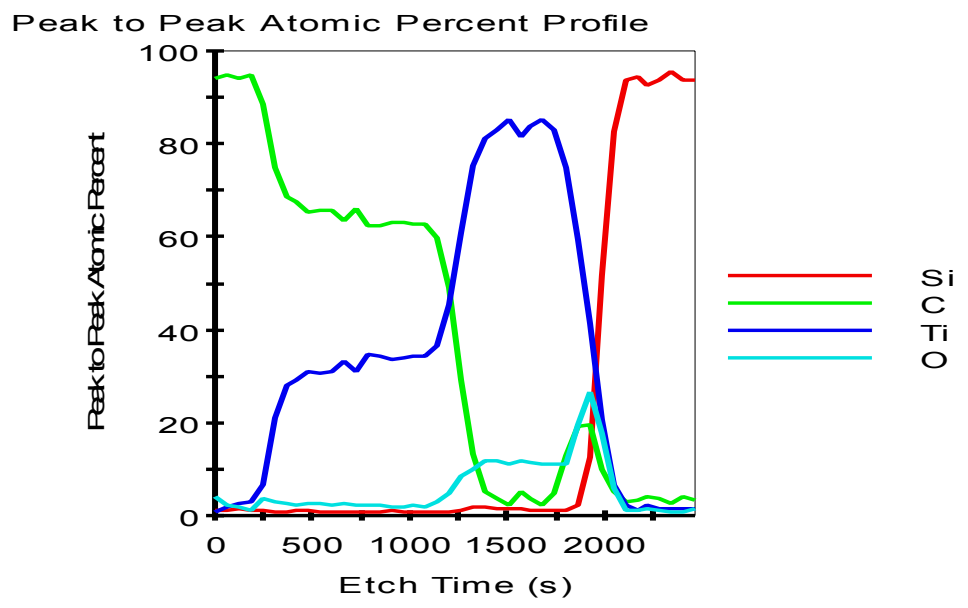

Fig. 3. Investigation of gradient of the chemical composition made by AES. 


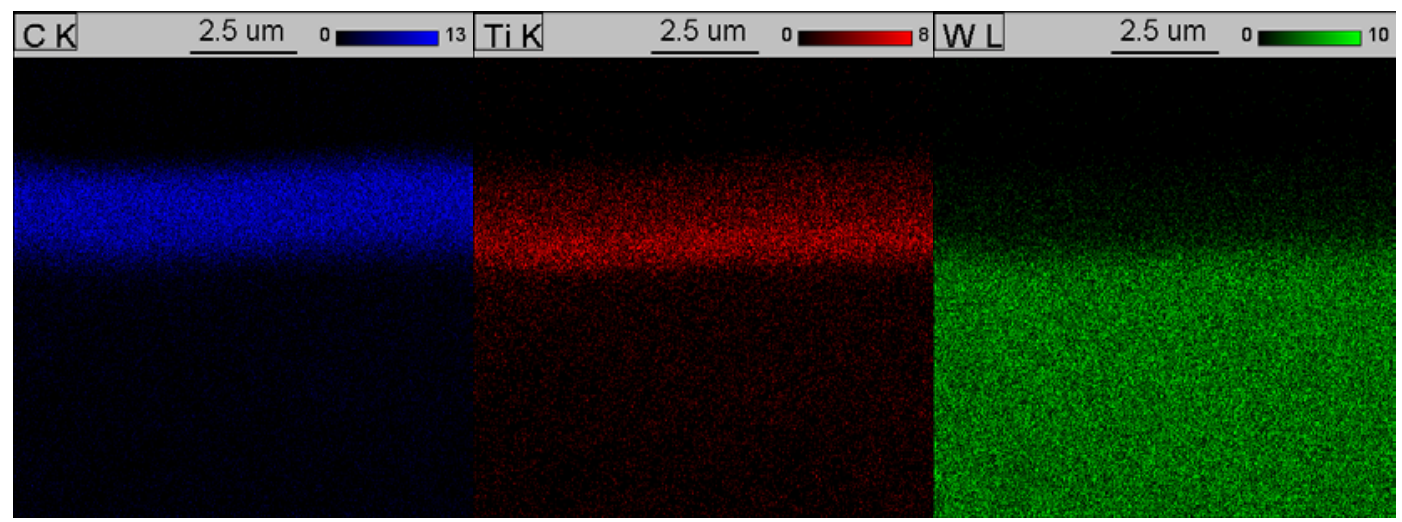

Fig. 4. Elements distribution map obtained by SEM.

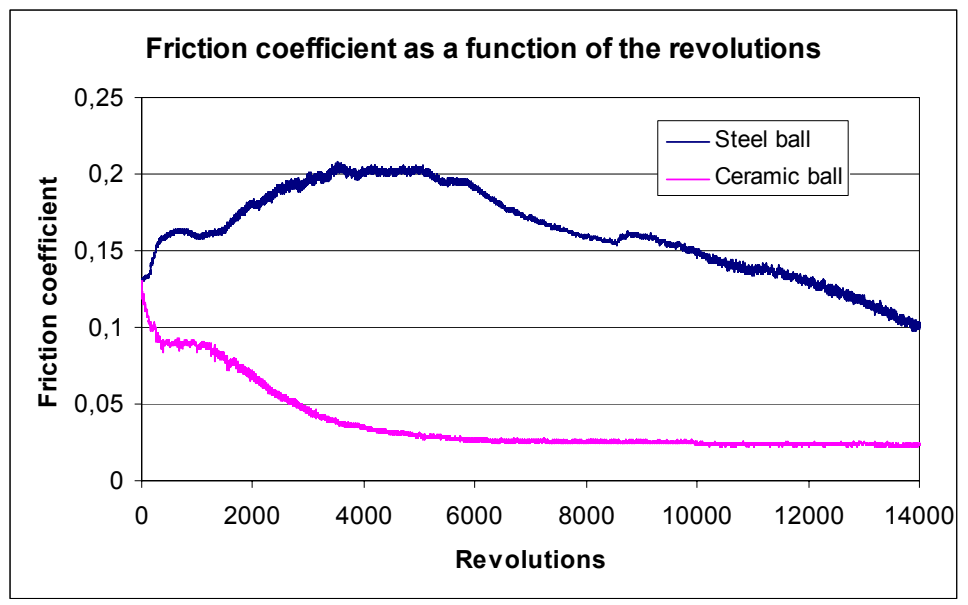

Fig. 5. Friction coefficients examined by the ball-on-disc method.
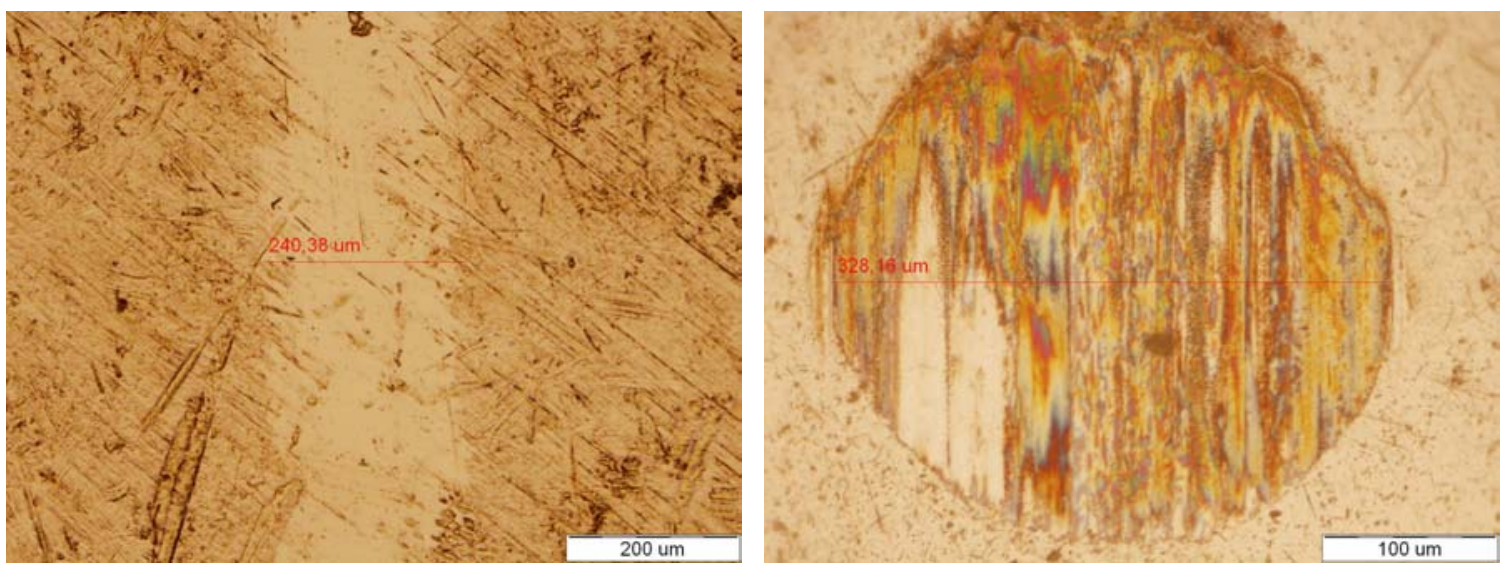

Fig. 6a, 6b Optical microscope investigation results: a) for the layer b) for the ball. 


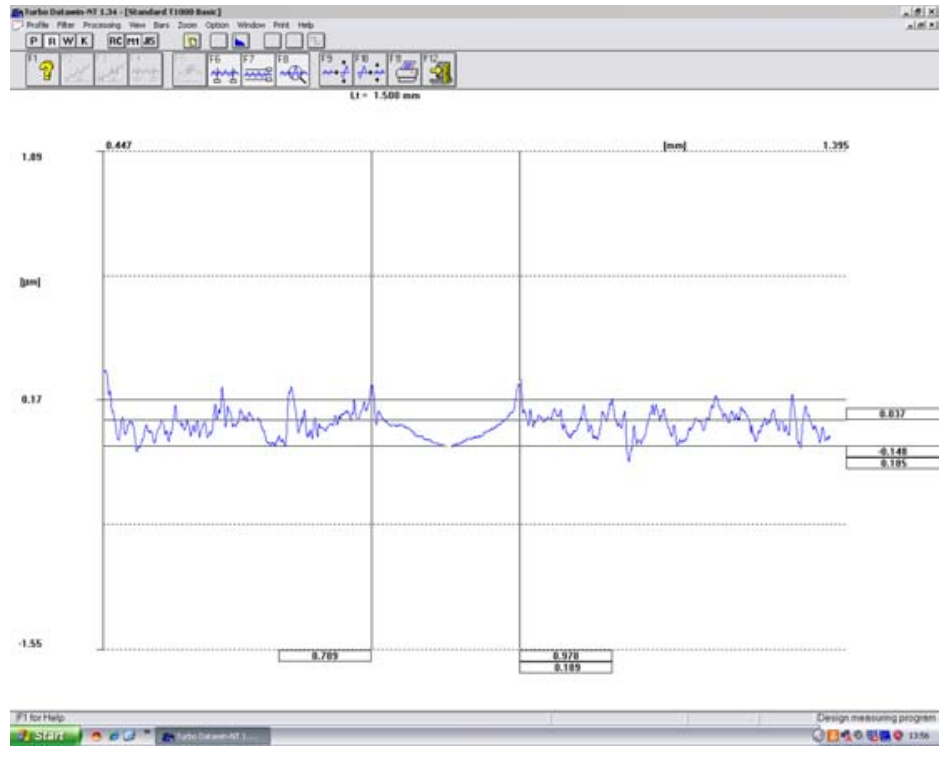

Fig. 7. Profile of the wear track obtained after the ball-on-disc investigation with use of the ceramic ball and $20 \mathrm{~N}$ load. 